\title{
URINARY AND FAECAL ESCHERICHIA COLI O-SERO- GROUPS IN SYMPTOMATIC URINARY-TRACT INFECTION AND ASYMPTOMATIC BACTERIURIA
}

\author{
A. P. Roberts, J. D. Linton, A. M. Waterman, P. E. Gower, AND \\ K. G. Koutsaimanis \\ Department of Medicine, Charing Cross Hospital Medical School, \\ Fulham Palace Road, London W6
}

IN the majority of cases of symptomatic urinary-tract infection occurring in non-pregnant women in domiciliary practice, the Escherichia coli O-serogroup causing the infection is also present in the patient's faecal flora (Turck, Petersdorf and Fournier, 1962; Vosti et al., 1964; Grüneberg, Leigh and Brumfitt, 1968). This correspondence between urinary and faecal O-groups is likely to occur by chance in only a small proportion of patients. It is therefore implied that the source of the organism infecting the urine is the patient's own faecal flora, which does not change with respect to the urinary O-group from the time the infection becomes established until it is detected. If a significant proportion of these symptomatic infections in non-pregnant women arises from pre-existing asymptomatic bacteriuria, as is the case in pregnancy (see Beard and Roberts, 1968), correspondence between urinary and faecal O-groups should also be found in non-pregnant women with asymptomatic bacteriuria. The previous studies, however, have either dealt exclusively with symptomatic patients (Turck et al., 1962; Grüneberg et al., 1968) or have not considered asymptomatic patients separately (Vosti et al., 1964). In the present study, the correspondence between urinary and faecal $E$. coli O-groups has therefore been assessed in non-pregnant women with either symptomatic urinary-tract infection or asymptomatic bacteriuria.

\section{MATERIALS AND METHODS}

Patients. Initially, women attending an out-patient clinic for urinary-tract infections were studied. Patients attending the clinic for the first time and those known to have been free of bacteriuria at their previous visit to the clinic 1 month to 1 year earlier, were included. None of the patients had been in hospital during the previous 6 months, nor had they received antibiotics during the previous month. Subsequently, in order to see if the results were more generally applicable, women presenting with symptomatic urinary-tract infection in a general practice and patients found to have asymptomatic bacteriuria during a screening programme at "well woman" clinics were also studied.

Urine was obtained by suprapubic aspiration as described by Beard et al. (1965) or as a midstream specimen after vulval cleansing with sterile water (Roberts, Robinson and Beard, 1967). From the patients attending the urinary-infection clinic, a rectal swab was taken followed by a suprapubic aspirate of urine if the patient was symptomatic, or a midstream specimen of urine if the patient had no symptoms. When the results from a midstream-urine

Received 2 Aug. 1974; amended version accepted 14 Oct. 1974.

J. MED. MICROBIOL.-VOL. 8 (1975) 
specimen were suggestive of bacteriuria the patient was recalled for suprapubic aspiration of urine. In those patients from whom a suprapubic aspirate could not be obtained, at least three midstream-urine specimens were collected before starting treatment. Patients presenting with symptoms of urinary-tract infection in the general practice had a rectal swab taken followed by a suprapubic aspirate and a midstream specimen of urine. In the well-woman clinics a rectal swab and a midstream specimen of urine were obtained at the first visit. If the results from the midstream urine were suggestive of bacteriuria the patient was recalled to the clinic for a second urine specimen and, if the original finding was confirmed, the patient was asked to attend the hospital for a suprapubic aspiration of urine; these patients were only included in the present study if the results from the suprapubic aspirate confirmed the findings from the midstream urines.

\section{Bacteriological procedures}

Urine specimens were plated on blood agar and MacConkey agar; the viable count was estimated by the filter-paper-strip method (Leigh and Williams, 1964) with CLED Medium (Oxoid Ltd) instead of MacConkey's agar. If a pure growth of $E$. coli was obtained from a suprapubic aspirate, this was considered as evidence of bacteriuria regardless of the viable count; in our experience this has always been endorsed by the findings from subsequent midstream or catheter specimens of urine. For the few patients from whom a suprapubic aspirate was not obtained, the diagnosis of bacteriuria was based on obtaining three consecutive midstream specimens of urine containing more than $10^{5}$ organisms per $\mathrm{ml}$. A single colony isolated from the culture of each specimen was used to determine the O-serogroup.

Rectal swabs were plated on blood agar and MacConkey agar; 10 colonies having the appearances of $E$. coli were chosen at random from the blood-agar plate unless a swarming Proteus sp. was present, in which case the MacConkey plate was used. Each picked colony was " streaked-out" and cultured and then re-picked as a check for purity. In two cases, five of the 10 colonies were later identified as Klebsiella spp. and in one case two colonies were identified as non-swarming Proteus sp.

Characterisation of bacteria. The identity of all isolates was initially determined on the basis of microscopic and colonial morphology, Gram-staining reaction and behaviour in standard biochemical tests (Cowan and Steel, 1965); organisms that were non-motile, nonlactose-fermenting or anaerogenic were, however, regarded as $E$. coli if the results were otherwise consistent with this conclusion. Antisera against the $10 \mathrm{E}$. coli $\mathrm{O}$-serogroups most commonly associated with urinary tract infection $(01,02,04,06,07,09,011,018,039$ and 075, Grüneberg et al., 1968) were prepared by the Biological Reagents Section, Center for Disease Control, Atlanta; these all reacted at titres of 1280 or greater with the homologous organism and none showed heterologous reactions at titres of 1000 or greater. For the purposes of this study, smooth isolates of $E$. coli that failed to agglutinate with any of the 10 available antisera, and isolates that agglutinated in saline alone, were designated nontypable. Faecal and urinary strains isolated from the same patient and found to belong to the same O-group were considered to correspond; strains found to belong to different O-groups were regarded as not corresponding. Non-typable isolates could not be considered as showing either correspondence or not with other non-typable isolates but were regarded as not corresponding with typable strains.

\section{RESULTS}

A total of 109 patients with bacteriuria were studied, of which 61 were attending the urinary-tract-infection (UTI) clinic; in 14 symptomatic patients and 17 asymptomatic patients, i.e. 31 of the 61 UTI-clinic patients, the urine was infected with a non-typable organism and at least one isolate from each rectal swab was also non-typable so that no decision could be made as to whether or not correspondence occurred. Of the remaining 30 UTI-clinic patients, 
16 were symptomatic and 14 were asymptomatic. Similarly, in 20 of the asymtomatic patients from well-woman (WW) clinics and eight of 18 symptomatic patients from general practice (GP) no decision could be made because nontypable isolates occurred at both sites.

The degree of correspondence between urinary and faecal isolates for all cases in which a decision could be made is shown in table I. The results are expressed in terms of the proportion of faecal isolates (ten from all but three patients) that corresponded in O-group with the urinary strain. The proportion is expressed as a percentage in order to accommodate the three cases in which, for technical reasons explained in Methods, fewer than 10 faecal $E$. coli colonies were isolated; the authors acknowledge the danger of expressing small numbers as percentages.

The results from both groups of symptomatic patients were similar; the urinary O-group was generally present in the patient's faecal flora and often accounted for half or more of the faecal isolates. The asymptomatic groups were very different from the symptomatic patients but were similar to each other in that the urinary O-group rarely corresponded with any of the faecal isolates. In $20(77 \%)$ of the 26 symptomatic patients the urinary O-group was present in the faecal flora, but in the 24 asymptomatic patients the urinary O-group was present in the faeces of only five $(21 \%)$; this difference in distribution is highly significant $\left(\chi^{2}=13.54, \mathrm{P}<0.001\right)$.

The O-groups of the urinary and faecal $E$. coli isolates are shown in table II; no E. coli $\mathrm{O} 39$ strain was isolated in the present study. In 46 of the 50 patients referred to in table $I$ the urine was infected with an organism that was typable with the 10 available antisera; in each of the remaining four patients the urine was infected with a non-typable $E$. coli but all 10 faecal isolates belonged to a specific O-group. The frequency of the various $\mathrm{O}$ groups amongst the urinary isolates showed no marked differences from the frequencies reported previously (see Grüneberg et al., 1968). In general, the distributions of the serogroups among the faecal and urinary isolates were similar. Although group $\mathrm{O} 1$ occurred more frequently and $\mathrm{O} 6$ less frequently

TABLE I

The degree of correspondence between urinary and faecal isolates of Escherichia coli for all patients in whom a decision could be made

\begin{tabular}{c|cccc}
\hline $\begin{array}{c}\text { Percentage of faecal } \\
\text { isolates corresponding } \\
\text { in O-group with the } \\
\text { urinary strain }\end{array}$ & $\overbrace{\text { symptomatic }}^{\text {urinary-tract infection }} \begin{array}{c}\text { Number of patients from each population in } \\
\text { clinic: }\end{array}$ & $\begin{array}{c}\text { well-woman } \\
\text { clinic: } \\
\text { symptomatic }\end{array}$ & $\begin{array}{c}\text { general } \\
\text { practice: } \\
\text { asymptomatic }\end{array}$ \\
\hline $10-49$ & 5 & 12 & 7 & 1 \\
$50-100$ & 3 & 1 & 1 & 3 \\
$0-100$ & 8 & 1 & 2 & 6 \\
\hline
\end{tabular}


TABLE II

O-groups of urinary and faecal E. coli isolates

\begin{tabular}{|c|c|c|}
\hline \multirow[b]{2}{*}{ O-group } & \multicolumn{2}{|c|}{ Number (and percentage)* of } \\
\hline & $\begin{array}{l}\text { urinary isolates of the } \\
\text { stated group }\end{array}$ & $\begin{array}{l}\text { faecal isolatest of the } \\
\text { stated group }\end{array}$ \\
\hline $\begin{array}{l}\text { O1 } \\
\text { O2 } \\
\text { O4 } \\
\text { O6 } \\
\text { O7 } \\
\text { O9 } \\
\text { O11 } \\
\text { O18 } \\
\text { O75 }\end{array}$ & $\begin{array}{r}6(13 \cdot 0) \\
5(10 \cdot 9) \\
3 \quad(6 \cdot 5) \\
13(28 \cdot 3) \\
4(8 \cdot 7) \\
1 \quad(2 \cdot 2) \\
0 \quad 37 \\
4(8 \cdot 7) \\
10(21 \cdot 7)\end{array}$ & $\begin{array}{r}13(21 \cdot 0) \\
4 \quad(6 \cdot 4) \\
4(6 \cdot 4) \\
12(19 \cdot 4) \\
5(8 \cdot 1) \\
2(3 \cdot 2) \\
3(4 \cdot 8) \\
8(12 \cdot 9) \\
11(17 \cdot 7)\end{array}$ \\
\hline Total " typable" & 46 & 62 \\
\hline
\end{tabular}

* The percentage figure is given for the number of isolates of the given O-group out of the total number of typable strains isolated from the stated source.

$\dagger$ Only one representative of any particular $\mathbf{O}$-group has been counted from each rectal swab; these isolates include two $\mathrm{O1}$, one $\mathrm{O} 2$, one $\mathrm{O6}$, two $\mathrm{O} 7$, one $\mathrm{O} 9$, one $\mathrm{O11}$, three $\mathrm{O} 18$ and two 075 strains from patients with a non-typable urinary strain and at least one non-typable faecal isolate.

amongst the faecal organisms, neither of these differences was statistically significant $\left(\chi^{2}=0.6625, \mathrm{P}>0.4\right.$ and $\chi^{2}=0.7299, \mathrm{P}>0.3$ respectively). The faecal isolates include 13 strains (two 01 , one 02 , one 06 , two 07 , one 09 , one 011 , three 018 and two 075 ) from patients who had a non-typable urinary strain and yielded one or more non-typable faecal isolates.

In table III the faecal isolates that corresponded with the urinary isolate and those that did not have been considered separately. For most groups the numbers are too small for valid comparisons to be made, but of the three major groups, O1 and 075 occurred with similar frequency whether they corresponded with the urinary strain or not. Group 06, however, accounted for nine $(36 \%)$ of the 25 faecal isolates corresponding with the urinary strain but for only three $(8 \%)$ of the 37 faecal isolates that did not correspond with the urinary strain; this difference is statistically significant $\left(\chi^{2}=5.756, P<0.02\right)$.

In the preparation of the data given in tables II and III, only one representative of any particular O-group has been counted from each rectal swab, and it may be argued that a more valid assessment of the faecal frequency of an O-group would be made by considering all the colonies that were isolated; when this is done (table IV), the frequencies of the various O-groups are relatively unchanged. Amongst the total (faecal) colonies of serogroups corresponding with the urinary strain, however, there was an increased frequency of groups $\mathrm{O} 1, \mathrm{O} 2$, and $\mathrm{O6}$ compared with that for single isolates of these groups.

\section{Discussion}

It was apparent from the initial study of patients in the urinary-tractinfection clinic that the majority of symptomatic patients showed correspon- 
TABLE III

O-groups of representative faecal E. coli isolates* corresponding with the urinary strain compared with those of representative faecal isolates differing from the urinary strain

\begin{tabular}{|c|c|c|}
\hline \multirow{2}{*}{ O-group } & \multicolumn{2}{|c|}{$\begin{array}{l}\text { Number (and percentage) of faecal isolates of the } \\
\text { stated group }\end{array}$} \\
\hline & $\begin{array}{l}\text { corresponding with } \\
\text { urinary isolate }\end{array}$ & $\begin{array}{c}\text { not corresponding } \\
\text { with urinary isolate } \dagger\end{array}$ \\
\hline $\begin{array}{l}\text { O1 } \\
\text { O2 } \\
\text { O4 } \\
\text { O6 } \\
\text { O7 } \\
\text { O9 } \\
\text { O11 } \\
\text { O18 } \\
\text { O75 }\end{array}$ & $\begin{array}{l}5(20 \cdot 0) \\
2(8 \cdot 0) \\
0 \quad \dddot{0} 0 \\
9(36 \cdot 0) \\
2(8 \cdot 0) \\
1 \quad(4 \cdot 0) \\
0 \quad \dddot{0} \\
1 \quad(4 \cdot 0) \\
5(20.0)\end{array}$ & $\begin{array}{l}8(21 \cdot 6) \\
2(5 \cdot 4) \\
4(10 \cdot 8) \\
3 \quad(8 \cdot 1) \\
3 \quad(8 \cdot 1) \\
1 \quad(2 \cdot 7) \\
3 \quad(8 \cdot 1) \\
7(18 \cdot 9) \\
6(16 \cdot 2)\end{array}$ \\
\hline Total " typable" & 25 & 37 \\
\hline
\end{tabular}

* Only one representative of any particular O-group has been counted from each rectal swab.

$\dagger$ These isolates include two 01 , one 02 , one 06 , two 07 , one 09 , one 011 , three 018 , and two 075 strains from patients with a non-typable urinary strain and at least one non-typable faecal isolate.

dence between their urinary and faecal $E$. coli O-groups whereas most asymptomatic patients did not. Because this difference was confirmed in the further studies of symptomatic patients from a general practice and asymptomatic patients from well-woman clinics, it is likely to be a feature of bacteriuria in non-pregnant women generally. These results only apply directly to patients with bacteriuria associated with $E$. coli strains of the O-groups that we have studied and to patients in whom all the faecal isolates belong to these O-groups. However, because these O-groups account for $40-70 \%$ of urinary isolates and a similar proportion of faecal isolates (Grüneberg et al., 1968) we do not consider that this is a serious limitation. Furthermore, a close correspondence between urinary and faecal isolates in symptomatic patients was also found when over 130 O-groups were studied (Turck et al., 1962; Grüneberg et al., 1968).

It has been re-emphasised recently (Cooke, 1974) that correspondence between urinary and faecal O-groups may be due to contamination of the faecal specimen with infected urine at the time of collection, or to subsequent colonisation of the faeces with the urinary strain. The possibility of contamination has been reduced by sampling the faecal flora with rectal swabs rather than by collecting stool specimens. The possibility of the urine becoming infected, from some exogenous source, with a strain that subsequently becomes established in the faecal flora has been considered as unlikely (Vosti et al., 1964), but has not been excluded by previous work. The results of the present study make the hypothesis of colonisation of the gut from the urinary tract more difficult to support, because it must now include a satisfactory explanation of the difference in the degree of correspondence between urinary and faecal strains in symptomatic and asymptomatic patients. It may be suggested 
TABLE IV

O-groups of all " typable" faecal E. coli colonies isolated*

\begin{tabular}{|c|c|c|c|}
\hline \multirow{2}{*}{ O-group } & \multicolumn{3}{|c|}{$\begin{array}{l}\text { Number (and percentage) of faecal isolates of the } \\
\text { stated group }\end{array}$} \\
\hline & $\begin{array}{l}\text { corresponding with } \\
\text { urinary isolate }\end{array}$ & $\begin{array}{l}\text { not corresponding } \\
\text { with urinary isolate }\end{array}$ & Total \\
\hline $\begin{array}{l}\text { O1 } \\
\text { O2 } \\
\text { O4 } \\
\text { O6 } \\
\text { O7 } \\
\text { O9 } \\
\text { O11 } \\
\text { O18 } \\
\text { O75 }\end{array}$ & $\begin{array}{c}40(25 \cdot 0) \\
20(12 \cdot 5) \\
0 \quad(\ldots . \\
66(41 \cdot 2) \\
9(5 \cdot 6) \\
1(<1) \\
0 \quad \ldots \\
1(<1) \\
23(14 \cdot 4)\end{array}$ & $\begin{array}{r}42(24 \cdot 6) \\
10(5 \cdot 8) \\
24(14 \cdot 0) \\
10(5 \cdot 8) \\
14(8 \cdot 2) \\
4(2 \cdot 3) \\
11(6 \cdot 4) \\
24(14 \cdot 0) \\
32(18 \cdot 7)\end{array}$ & $\begin{array}{rr}82 & (24 \cdot 8) \\
30 & (9 \cdot 1) \\
24 & (7 \cdot 2) \\
76 & (23 \cdot 0) \\
23 & (6 \cdot 9) \\
5 & (1 \cdot 5) \\
11 & (3 \cdot 3) \\
25 & (7 \cdot 6) \\
55 & (16 \cdot 6)\end{array}$ \\
\hline Total " typable" & 160 & 171 & 331 \\
\hline
\end{tabular}

* Of the total 1058 faecal colonies isolated, 727 were " non-typable" with the 10 available antisera.

that " retrograde" colonisation of the faeces would become more likely the longer the bacteriuria had been established; a development of that argument would be to infer that the majority of symptomatic patients have been infected for long enough for this to occur, whereas asymptomatic bacteriuria would have to be of relatively recent origin. The present study cannot conclusively disprove this suggestion, but several symptomatic patients were known to have been free of bacteriuria less than three months previously, and a number of asymptomatic patients gave a history of minimal signs, such as offensively smelling urine, that had been continuous for several years. The study also indicates ways in which this question could be finally resolved. Follow-up of untreated patients with asymptomatic bacteriuria would show whether any initial correspondence was lost or if correspondence, which was lacking initially, occurred with time. If successfully treated patients were followed up at short intervals until infection occurred again, it would be apparent whether or not recently acquired bacteriuria showed correspondence with the faecal flora.

If the usual interpretation of correspondence between urinary and faecal O-groups (Turck et al., 1962; Vosti et al., 1964; Grüneberg et al., 1968) is correct, our results could indicate that a symptomatic infection arises from organisms in the patient's faecal flora, whereas asymptomatic bacteriuria arises from some exogenous source. A more likely explanation, however, is that in both cases the infection arises from the faecal flora present in the patient at that time but because the faecal O-groups change at intervals (see for example, Sears, Brownlee and Uchiyama, 1950), this correspondence has in general been lost when asymptomatic bacteriuria is detected by chance in a screening programme or at a routine visit to a clinic. 
If the latter explanation is correct, our findings imply that when symptoms are to develop they do so in most cases within a short time of the infection becoming established whereas in most cases of asymptomatic bacteriuria the infection has been established long enough for the faecal flora to change. It is therefore unlikely that a significant period of asymptomatic bacteriuria precedes the development of symptoms in most cases of urinary-tract infection. If this is correct, the detection and treatment of asymptomatic bacteriuria in non-pregnant women would not significantly reduce the incidence of symptomatic urinary-tract infection in this population. Evidence in support of this view was given by Asscher and his co-workers (Asscher et al., 1969; Sussman et al., 1969), who screened 3,578 non-pregnant women and found $107(3 \%)$ with bacteriuria. Of the bacteriuric patients followed for up to 12 months, $36 \%$ developed symptoms of urinary-tract infection, although in over half of them the bacteriuria had been treated. Of 88 non-bacteriuric (control) women, six developed symptoms within 12 months and in three of them bacteriuria was confirmed. If this control group was representative of non-bacteriuric women in general, approximately 120 women would have developed symptomatic urinary-tract infection within 1 year of being found free of bacteriuria compared with less than 40 women amongst those with bacteriuria.

The results of the present work indicate that a study of the correspondence between urinary and faecal O-groups in bacteriuria of pregnancy would be valuable. If correspondence was found in asymptomatic bacteriuria detected in early pregnancy this would suggest a relatively recent origin-possibly in the early weeks of pregnancy rather than preceding it; it would be particularly interesting to discover whether or not these are the patients who subsequently develop symptoms.

The frequency of group $\mathrm{O} 6$ in the faecal flora of our patients with infected urine contrasts with the relatively low prevalence of this O-group in the faecal flora of uninfected patients (Grüneberg et al., 1968). However, although group O6 showed correspondence between urinary and faecal isolates more frequently than the other O-groups, we found it relatively infrequently in the faecal flora of patients with urinary-tract infection caused by $E$. coli strains of other O-groups. This finding adds support to the view (Grüneberg et al., 1968). that group $\mathrm{O6}$ may be especially pathogenic for the urinary tract.

\section{SUMMARY}

The degree of correspondence between urinary and faecal Escherichia coli O-groups has been assessed in non-pregnant women with symptomatic urinary-tract infection or asymptomatic bacteriuria.

In 20 of 26 patients with symptomatic urinary tract infection $E$. coli of the same O-group as that of the urinary infecting strain was also present in the patient's faecal flora whereas such a correspondence was found in the faecal flora of only five of 25 patients with asymptomatic bacteriuria. This finding indicates that the majority of episodes of symptomatic urinary tract infection 
in non-pregnant women are not preceded by a significant period of asymptomatic bacteriuria.

E. coli $\mathrm{O} 6$ showed correspondence between urinary and faecal isolates more frequently than did other O-groups, but it had a relatively low prevalence in the faecal flora of patients with urinary-tract infection caused by $E$. coli of other O-groups. This finding lends support to previous suggestions that $E$. coli $\mathrm{O} 6$ may be especially pathogenic for the urinary tract.

We wish to thank Drs G. A. Dove and A. J. Bailey for supplying the general-practice specimens, and Miss G. A. Stacey for collecting the specimens at well-woman clinics, and for technical assistance. This work was supported in part by a grant from the Clinical Research Committee, Charing Cross Hospital. The O-antisera used in this study were prepared and supplied by the Biological Reagents Section, Center for Disease Control, Atlanta, USA.

\section{REFERENCES}

Asscher, A. W., Sussman, M., Waters, W. E., Evans, J. A. S., Campbell, H., Evans, K. T. AND Williams, J. E. 1969. Asymptomatic significant bacteriuria in the non-pregnant woman. II. Response to treatment and follow-up. Br. med. J., 1, 804.

BEARD, R. W. AND RoberTS, A. P. 1968. Asymptomatic bacteriuria during pregnancy. Br. med. Bull., 24, 44.

Beard, R. W., McCoy, D. R., Newton, J. R. and Clayton, S. G. 1965. Diagnosis of urinary infection by suprapubic bladder puncture. Lancet, $2,610$.

Cooke, E. M. 1974. Escherichia coli and man, Edinburgh and London, p. 39.

CowAN, S. T. AND STEEL, K. J. 1965. Manual for the identification of medical bacteria, London.

GRÜNEBERG, R. N., LEIGH, D. A. AND BRUMFITT, W. 1968. Escherichia coli serotypes in urinary tract infection: studies in domiciliary, antenatal and hospital practice. In Proceedings of the first national symposium on urinary tract infection, edited by F. O'Grady and W. Brumfitt, London, p. 68.

Leigh, D. A. AND Williams, J. D. 1964. Method for the detection of significant bacteriuria in large groups of patients. J. clin. Path., 17, 498.

Roberts, A. P., Robinson, R. E. AND Beard, R. W. 1967. Some factors affecting bacterial colony counts in urinary infection. Br. med. J., 1, 400 .

Sears, H. J., Brownlee, I. AND Uchiyama, J. K. 1950. Persistence of individual strains of Escherichia coli in the intestinal tract of man. J. Bact., 59, 293.

Sussman, M., Asscher, A. W., Waters, W. E., Evans, J. A. S., Campbell, H., Evans, K. T. AND Williams, J. E. 1969. Asymptomatic significant bacteriuria in the non-pregnant woman. I. Description of a population. Br. med. J., 1, 799.

Turck, M., Petersdorf, R. G. AND Fournier, M. R. 1962. The epidemiology of non-enteric Escherichia coli infections: prevalence of serological groups. J. clin. Invest., 41, 1760.

Vosti, K. L., Goldberg, L. M., Monto, A. S. and Rantz, L. A. 1964. Host parasite interaction in patients with infections due to Escherichia coli. I. The serogrouping of $E$. coli from intestinal and extraintestinal sources. J. clin. Invest., 43, 2377. 